\title{
Multidisciplinary analysis of CROR propulsion systems: DLR activities in the JTI SFWA project
}

\author{
A. Stürmer • R. A. D. Akkermans
}

Received: 8 November 2013/Revised: 5 March 2014/Accepted: 6 March 2014/Published online: 26 March 2014 (c) The Author(s) 2014. This article is published with open access at Springerlink.com

\begin{abstract}
In the frame of the EU 7th Framework Joint Technology Initiative Smart Fixed Wing Aircraft project, the DLR Institute of Aerodynamics and Flow Technology (DLR-AS) is participating as an associated partner in the Airbus-led studies of the Contra-Rotating Open Rotor (CROR) as possible powerplant for future transport aircraft. Due to significant technical challenges in terms of noise emissions, installation effects and certification that still need to be addressed for this novel propulsion system, the numerical activities require the use of sophisticated multidisciplinary analysis tools and approaches covering aerodynamics, aeroacoustics and aeroelastics. In this paper an overview of the DLR-AS work in the project is given, which covers the numerical assessment of a novel noise reduction technology, an initial study of blade aeroelasticity as well as some in-depth studies on isolated and installed pusher-configuration CROR engine configurations. The first results of a validation of the numerical simulations using experimental test data that is being generated in Airbus-led low-speed wind tunnel tests are also presented.
\end{abstract}

Keywords Contra-rotating open rotor (CROR) uRANS · Aerodynamics · Aeroacoustics · Aeroelasticity

This paper is based on a presentation at the German Aerospace Congress, September 10-12, 2013, Stuttgart, Germany.

A. Stürmer $(\bowtie) \cdot$ R. A. D. Akkermans

DLR Institut für Aerodynamik und Strömungstechnik,

Lilienthalplatz 7, 38108 Braunschweig, Germany

e-mail: arne.stuermer@dlr.de

\author{
List of symbols \\ $B_{\mathrm{A}} \quad$ Aft rotor blade passing frequency \\ $B_{\mathrm{F}} \quad$ Front rotor blade passing frequency \\ $C_{\mathrm{P}} \quad$ Power coefficient, $C_{\mathrm{P}}=\mathrm{P} /\left(\rho n^{3} D^{5}\right)$ \\ $C_{\mathrm{F}} \quad$ Total force coefficient, \\ $C_{\mathrm{F}}=\left(C_{\mathrm{T}}^{2}+C_{\mathrm{Y}}^{2}+C_{\mathrm{Z}}^{2}\right)^{0.5}$ \\ $C_{\mathrm{L}} \quad$ Lift coefficient, $C_{\mathrm{L}}=F_{\mathrm{z}} /(q S)$ \\ $C_{\mathrm{T}, \mathrm{Y}, \mathrm{Z}}$ Thrust, lateral and lift coefficient, \\ $C_{\mathrm{T}, \mathrm{Y}, \mathrm{Z}}=F_{\mathrm{X}, \mathrm{y}, \mathrm{Z}} /\left(\rho n^{2} D^{4}\right)$ \\ $D \quad$ Front rotor diameter \\ $f \quad$ Frequency \\ $F_{\mathrm{x}, \mathrm{y}, \mathrm{z}} \quad$ Forces in Cartesian coordinate system \\ $M \quad$ Mach number \\ $n \quad$ Rotor rotational frequency \\ $P \quad$ Power \\ $q \quad$ Dynamic pressure, $\mathrm{q}=0.5 \rho \mathrm{V}_{0}^{2}$ \\ $r \quad$ Radial position \\ $R \quad$ Rotor radius \\ $S \quad$ Reference area \\ $V_{0} \quad$ Freestream velocity \\ $\mathrm{x}, \mathrm{y}, \mathrm{z} \quad$ Cartesian coordinate system positions
}

\section{Greek symbols \\ $\alpha \quad$ Angle of attack \\ $\Psi \quad$ Azimuth angle \\ $\rho$ Density \\ $\theta$ Polar angle}




\section{Introduction}

In the frame of the 7th Framework EU Joint Technology Initiative Smart Fixed Wing Aircraft project (JTI SFWA) [1], the DLR Institute of Aerodynamics and Flow Technology (DLR-AS) is contributing to a comprehensive investigation into the feasibility of Contra-Rotating Open Rotor (CROR) propulsion systems for future single-aisle transport aircraft. In order to improve the understanding of the complex flow physics as well as to advance the technical maturity of employing this type of engine as a powerplant in the context of stringent efficiency and certification requirements relating to performance, pollutant and noise emissions, DLR is employing a multidisciplinary numerical approach based on high-fidelity tools $[2,3]$. While the high bypass ratio of CROR engines results in a superior propulsive efficiency, their integration on an aircraft requires careful consideration of complex engineairframe interactions impacting performance, aeroelastics and aeroacoustics $[4,5]$. The focus configuration across all activities is the generic Airbus AI-PX7 pusher CROR configuration, a $11 \times 9$-bladed design featuring an aft rotor diameter reduction of $10 \%$ with respect to the front rotor [6]. This propulsion system is studied in three principal variants in various tasks of the project:

- A full-scale isolated CROR configuration, i.e. with an axisymmetric nacelle for the innovative blade and pylon design studies.

- A $1 / 5$ th scale wind-tunnel model, called Z49, which is being tested as an isolated CROR at cruise conditions in the ONERA S1 wind tunnel and will also be investigated at low-speed conditions in the DNW-LLF tunnel in both isolated and semi-installed (i.e. including a pylon) configurations.

- A 1/7th scale wind-tunnel model, called Z08, designed for a recently completed series of tests at low-speed conditions in the DNW-LLF wind tunnel in configurations ranging from isolated to semi-installed and fullyinstalled on the empennage of a representative T-tail aircraft configuration.

In the first discussion of results in this paper, the activities by DLR-AS in support of a task analyzing some novel technologies aimed at addressing CROR noise emissions on a fundamental level through an investigation of the general efficacy of employing front rotor trailing edge blowing for the reduction of CROR interaction tone noise emissions will be discussed. Another important field of work in the project, which could have a potentially significant impact on CROR performance and noise emissions, is the aeroelasticity of the rotor blades. In support of the preparation of the wind tunnel testing, DLR contributed to the definition of the blade jig shape utilizing a coupled simulation based on CFD and computational structural mechanics (CSM) tools, a step necessary to ensure the flexible blades operate in their design shape during the experimental test campaign.

Finally, drawing on wide-ranging experimental test campaigns using several CROR engine simulators at various scales, a major focus of the JTI SFWA activities is the robust validation of the unsteady computational fluid dynamics (CFD) simulations employing the DLR TAUCode and the coupled aeroacoustic analysis using the DLR APSIM+-Code [2, 3]. For low-speed conditions, the recent test of the Airbus-designed 1/7th-scale Z08-CROR provide a broad scope of data to assess the numerical methods' ability to properly predict the aerodynamic performance as well as the noise emissions of CROR engines as influenced by their integration on an airframe and the specific requirements placed on the numerical tools and approaches.

\section{Numerical approach}

With the issue of noise being a primary concern for the realization of a viable CROR propulsion system, most simulations performed by DLR-AS within the scope of the JTI SFWA project are typically coupled CFD-CAA simulations utilizing the DLR TAU-Code for the uRANS aerodynamic analysis and the DLR FWH-Code APSIM+ for the subsequent noise analysis.

\subsection{DLR TAU-Code CFD simulations}

The DLR TAU-Code is an unstructured finite-volume vertex-based CFD solver. For the simulation described here, spatial discretization of the convective fluxes is done using a second order central differencing scheme with scalar dissipation while the viscous fluxes are discretized with central differences. Turbulence is modeled with the 1-equation Spalart-Allmaras model [7]. The dual time approach is used in the DLR TAU-code to compute unsteady flows [8], while the relative motion of the rotors is handled using the code's Chimera capability as well as the implemented motion libraries [9].

\subsubsection{Mesh generation}

The typical approach for the mesh generation process for the CROR configurations studied in the JTI SFWA project is to use three Chimera blocks, which are generated using both the CentaurSoft Centaur and the ANSYS ICEM CFD mesh generation softwares. The nacelle mesh block, which has farfield boundaries typically located at a distance of 20 times the front rotor diameter from the engine axis and 
front rotor center, is a hybrid/unstructured mesh, as can be seen in Fig. 1. Both the front and aft rotor meshes on the other hand are block-structured grids. In addition to ensuring an adequate resolution of boundary layers (including the laminar sublayer) on all surfaces of the CROR, a particular focus of the mesh generation was the requirement to adequately resolve the aeroacoustic pressures in the rotor mesh blocks during the CFD simulation in order to use the nacelle Chimera boundary as the input permeable surface for the APSIM+ analysis. Therefore, the mesh density of the front and aft rotor grids was dictated by the need to resolve all relevant sound pressures typically through the 5 th harmonic of the front rotor blade passing frequency.

Typical mesh sizes for the configuration discussed in this paper are around 60 million nodes for an isolated CROR configuration, while the added modeling of the pylon leads to grids of around 70 million nodes.

\subsection{2 uRANS simulations}

The aerodynamic simulations follow an approach that has been successfully applied in a number of CROR simulations performed at DLR-AS in recent years. In a first step, a steady-state start-up simulation without any rotor motion is done to initialize the flowfield before the unsteady simulations are started. A successive refinement of the physical time-step size is done in the course of the simulation to speed up the achievement of a periodic state in the flow. For the final period, i.e. the final rotation of the rotors, typically a time-step size resulting in a $0.5^{\circ}$ rotation of the rotors is set. For isolated CROR configurations a converged

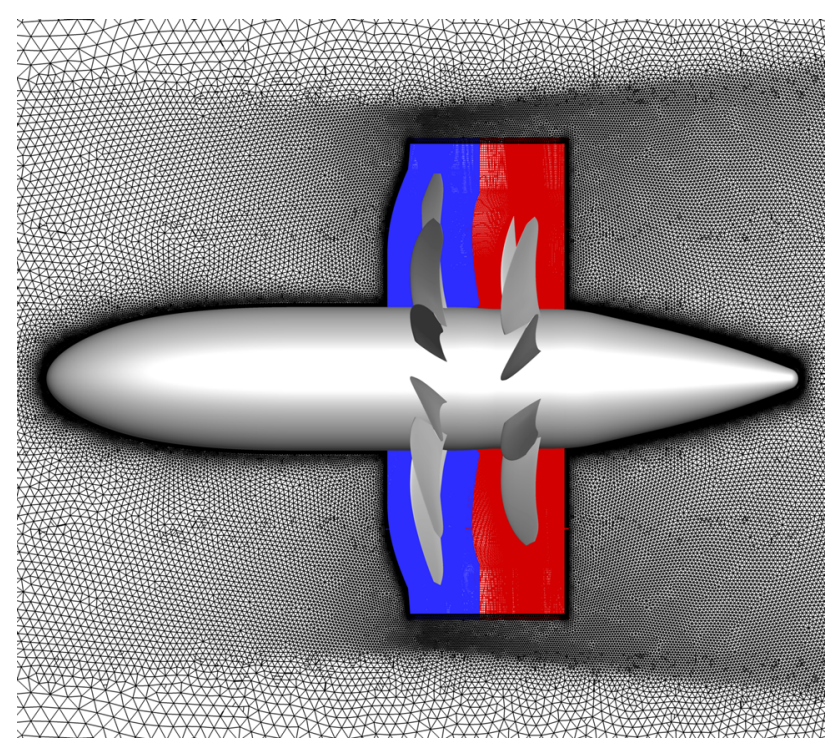

Fig. 1 Representative Chimera blocking strategy for the CFD simulations shown for the isolated AI-PX7 CROR periodic state is usually achieved after 5 rotor revolutions, while for cases including a pylon the achievement of periodic forces on the pylon normally requires computing 12 full periods. With the simulations run using between 360 and 720 CPUs of DLRs $C^{2} \mathrm{~A}^{2} \mathrm{~S}^{2} \mathrm{E}$ cluster, these simulations require between 2 and 4 weeks of runtime respectively. Results of the final rotation are then postprocessed for the aerodynamic analysis as well as for use in the aeroacoustic analysis.

\subsection{DLR APSIM+-Code CAA simulations}

The Aeroacoustic Prediction System based on Integral Method (APSIM+) was developed at the DLR Institute of Aerodynamics and Flow Technology for the prediction of rotor or propeller noise radiated in the free farfield. As mentioned, in the current applications the unsteady CFD data on the Chimera boundary surfaces surrounding the propellers is used for an aeroacoustic analysis based on the permeable surface Ffowcs-Williams/Hawkings (FWH) approach [10-12]. Shown as the translucent cylindrical surface in Fig. 2, this choice was made out of practical considerations, since this boundary represents an already existing closed surface which encloses the relevant noise sources of the geometry, i.e. the rotors. The noise contribution of the nacelle, which lies outside of the permeable surface, is not considered in the present APSIM+ computations. The calculations, which for the present JTI SFWA cases are performed in the time domain, deliver pressure amplitude and phase information at any desired observer location, which is further analyzed to derive acoustic spectrum data. For the overall sound pressure level

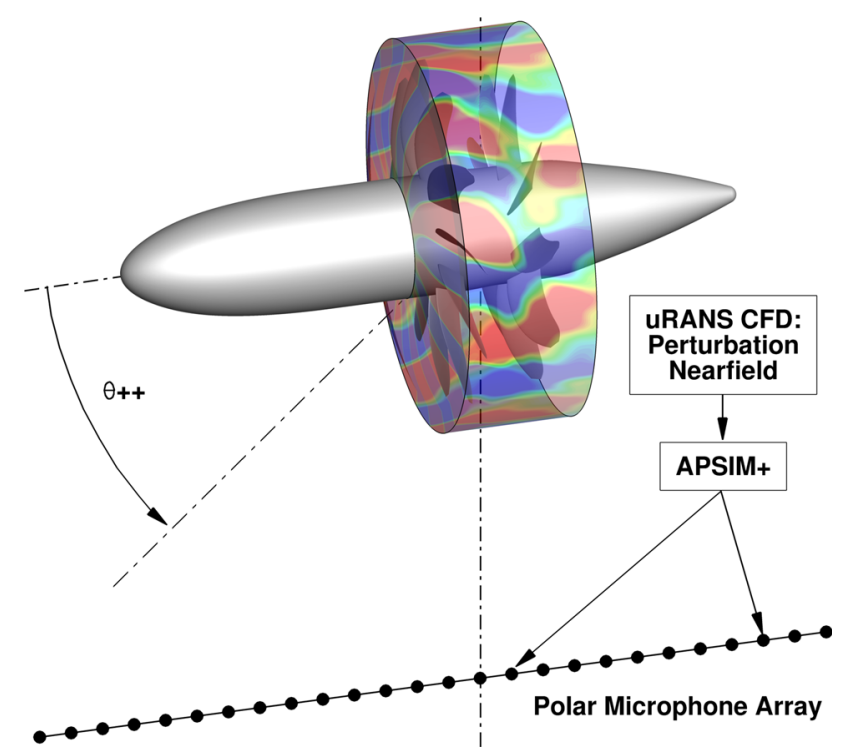

Fig. 2 TAU-APSIM+ coupling process and setup 
(OASPL), usually all frequencies up to five times the front rotor blade passing frequency $\left(f=5 B_{\mathrm{F}}\right)$ are considered. In this paper, unless otherwise noted, the CAA results are shown as farfield polar directivities for a virtual ground microphone array sketched in Fig. 2, which lies parallel to the engine axis at a distance of 11 front rotor diameters below the CROR configuration.

\section{Front rotor trailing edge blowing}

In the frame of the Airbus-led task 2.2.2.1 "Design of Innovative CROR Blade and Pylon", DLR-AS is investigating the general efficacy of applying front rotor trailing edge blowing (TEB) for the reduction of interaction tone noise emissions of CROR propulsion systems [13]. For this study, each blade of the AI-PX7 CROR's front rotor was modified to include a slot just upstream of the trailing edge on the blade suction side for much of the blade span. This slot is laid out as a backward facing step in order to facilitate an air injection tangential to the surface of the blade suction side. The investigations are focused on the isolated CROR at typical low-speed $M=0.23$ take-off conditions, for which interaction tone noise is a concern for the flyover noise certification [4].

Figure 3 compares the front blade wakes at an axial position of $x / D=0.08$ downstream of the front rotor in terms of the instantaneous dynamic pressure profiles at a radial position of $80 \%$ span of the front blade. The injection of air near the trailing edge along the front blade span serves to significantly reduce the wake deficit. In this initial assessment, the primary aim was to demonstrate the potential of front rotor blowing for CROR interaction tone

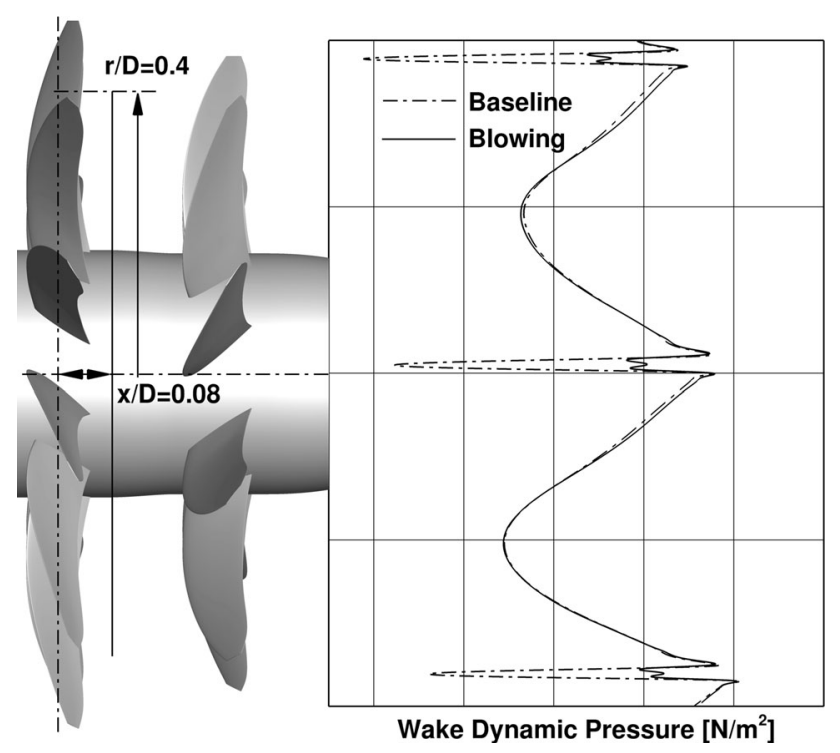

Fig. 3 Impact of TEB on front rotor blade wakes noise emission reductions. Thus, a wake filling was targeted for the entire aft blade span, resulting in a relatively large air massflow.

The success of this reduction in front blade wake strength can be seen in the reduced local loading fluctuations at a corresponding spanwise position of the aft blade, as plotted in Fig. 4. In comparison to the baseline case, the blowing configuration shows a significant reduction in the oscillations of the local blade loading coefficient. For this study, the baseline and the blowing case were investigated at identical blade pitch settings of the front and aft rotor. This was found to be acceptable as only a marginal impact on the CROR performance was found. The overall thrust is reduced by a mere $0.175 \%$. Figure 4 shows that the mean value of the aft blade loading is reduced for the active flow control case in comparison with the reference configuration. For the complete aft rotor, the reduction in average thrust is $2.215 \%$, while the blowing case shows an increase in front rotor mean thrust of $1.276 \%$.

Figure 5 shows the tonal decomposition of the noise emissions for a farfield microphone located in the front rotor plane. The black bars represent the baseline case, while the results of the active flow control case are shown in gray. Very little impact of the TEB application is seen in the front and aft rotor tones ("F" and "A"), which supports the previously stated observation that the slight difference in the mean front and aft rotor thrust levels between the two cases is negligible. On the other hand, notable reductions can be seen in most interaction tones.

Despite this apparent success in wake alleviation, the farfield ground noise directivity comparison in Fig. 6 reveals only a small peak noise reduction in the vicinity of the rotors, while a significant noise penalty is in fact found

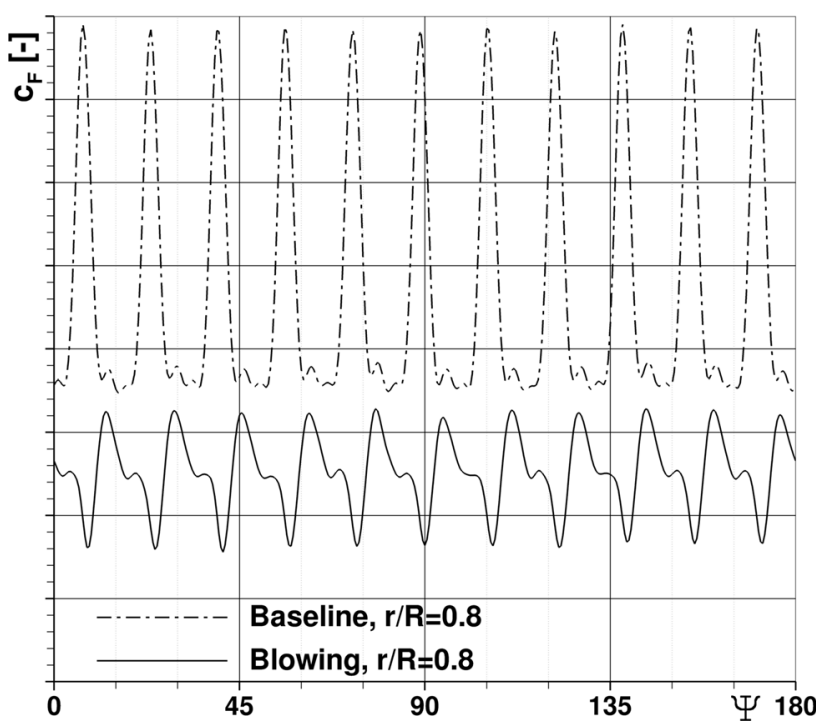

Fig. 4 Aft blade local loading oscillation reduction through application of front rotor trailing edge blowing 


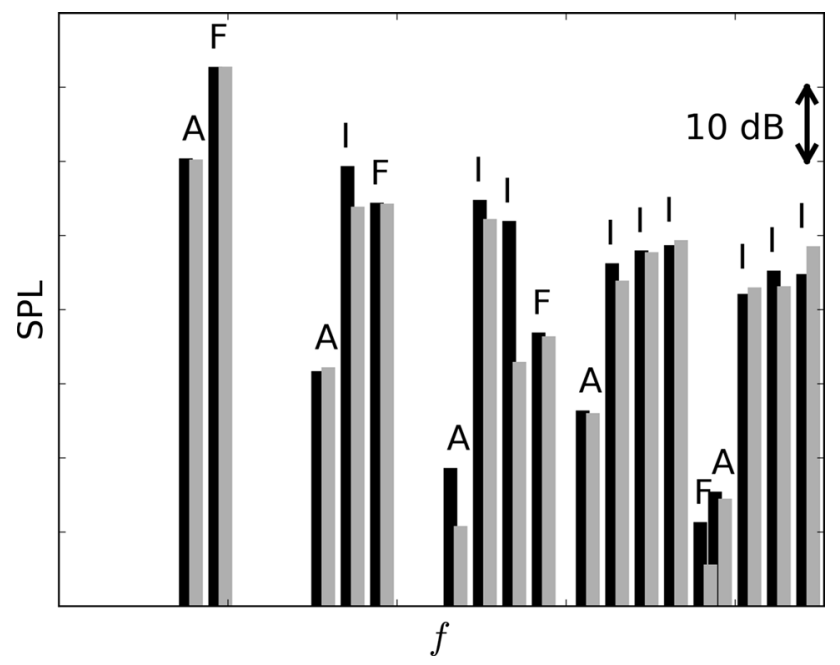

Fig. 5 Impact of front rotor trailing edge blowing on tonal noise spectra in the front rotor plane

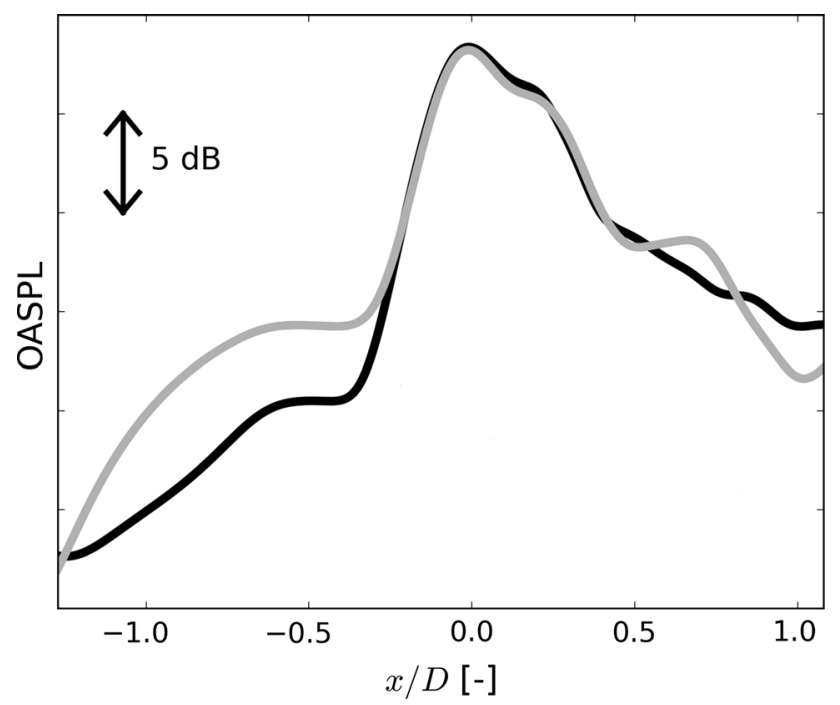

Fig. 6 Impact of TEB on ground noise directivities

in the upstream directions. As discussed in detail in [13], the primary reason for this is traceable to the only very moderate cropping of the aft rotor diameter of this particular CROR configuration. Thus front blade tip vortices still impinge on the aft blades and are in fact the primary source of interaction tone noise-which cannot be ameliorated through the reduction of the blade wakes. In order to further demonstrate the efficacy of front rotor TEB, a followup to this study was done, which utilized a generic CROR configuration developed by DLR-AS, which is presented in detail in another publication [14]. This CROR features an aft rotor crop of $15 \%$ versus the front rotor and thus fully avoids the interaction with the front blade tip vortices. The use of front rotor TEB in this case did in fact lead to a very pronounced reduction in noise emissions $(2.5 \mathrm{dBA}$ peak noise and up to $5 \mathrm{dBA}$ in the up- and downstream direction), substantiating the general efficacy of this flow control technology for interaction tone noise emissions for CROR applications.

\section{CROR blade aeroelastics}

Task 2.2.2.2, which is led by NLR, is focused on the analysis of the impact of blade deformation on the aerodynamic and aeroacoustic performance of the CROR. Aeroelasticity is especially important for CROR blades, since they tend to be thin for good performance at high Mach numbers and feature large sweep and twist, which leads to a coupling of the blade deformation in bend and twist. A complex combination of aerodynamic, centrifugal and Coriolis forces on the blades of a rotor needs to be properly accounted for in a multidisciplinary analysis of CROR propulsion systems. Aerodynamic and particularly the centrifugal forces due to rotor rotation have a strong impact on blade stiffness, notably impacting the structural eigenfrequencies and mode shapes, while the Coriolis forces have a damping effect. Initially this task was scoped to guide the design of the model scale rotors to ensure the blade shapes matched the design shapes under wind tunnel test operating conditions, in particular for the high-speed tests planned to be performed in the ONERA S1 tunnel. Thus numerous partners employed numerical methods to derive the so-called cold- or jig-shape of the front and aft rotor blades from the target shapes envisioned by Airbus for the AI-PX7 CROR design. Utilizing a finite element model delivered by task partner IBK, which was guided by the carbon fiber ply layup planned by NLR for the blade manufacturing, DLR-AS employed the non-linear hot-tocold analysis functionality provided by the SOL106 solver in the commercial NASTRAN FE-modeling software to compute the expected deflections of the blades under load. In addition to the pre-stressing effect of the centrifugal loading resulting from the high rotational speeds of the rotors at model scale, the mean blade pressure distributions are a necessary input to this approach. The latter was obtained through an averaging of the blade surface pressures from a uRANS simulation of the CROR at the expected operating conditions in the wind tunnel test, while the former is specified using the RLOAD card of NASTRAN. As shown for the example of an aft blade in Fig. 7, the deflections at the tip are small but measureable. Of note is the slight difference in the displacements of the blade at the tip leading and trailing edges, indicating a small amount of blade torsion under loads, which is important to account for to obtain proper aerodynamic performance in the wind tunnel test. 


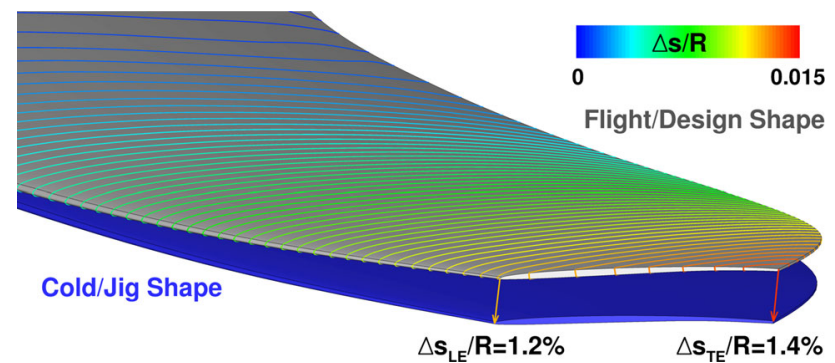

Fig. 7 1/5th scale aft blade tip deflection prediction

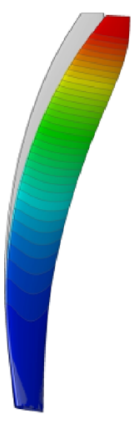

1st Bending

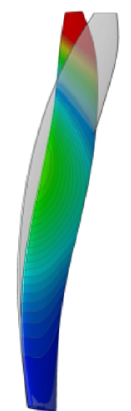

2nd Bending 1st Torsion

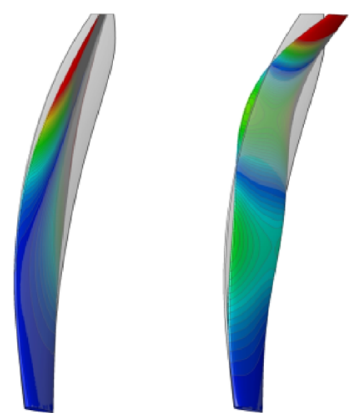

3rd Bending
Fig. 8 1/5th scale front blade mode shapes

Table 1 Eigenfrequency deviations in the numerical and experimental results for the $1 / 5$ th scale front blade

\begin{tabular}{lcccc}
\hline & Mode 1 & Mode 2 & Mode 3 & Mode 4 \\
\hline$\Delta$ f(FEM-EXP) & $-0.6 \%$ & $-0.4 \%$ & $-0.7 \%$ & $-2.2 \%$ \\
\hline
\end{tabular}

Figure 8 shows the first four mode shapes for the blade of a front rotor as computed in the NASTRAN analysis. In order to validate the FE-models dynamic properties, a comparison of the computed eigenfrequencies for a nonrotating blade with results of a "ping test" analysis of the actual manufactured blade is shown in Table 1. As listed, the first three eigenfrequencies are within $1 \%$ of the test results, with a larger deviation of $2.2 \%$ found for the fourth eigenfrequency. A possible reason for the latter deviation in an otherwise very good correlation is that the ply layup of the final manufactured blade was slightly altered versus that used in the FE-model.

Figure 9 shows the Campbell diagram for the investigated $1 / 5$ th scale front rotor blade, which plots the numerically computed development of the blade's eigenfrequencies with the rotational speed of the propeller. Clearly evident is the stiffening effect of the centrifugal loading on the blade, as the eigenfrequencies are seen to increase slightly as the propeller rotational speeds grow.

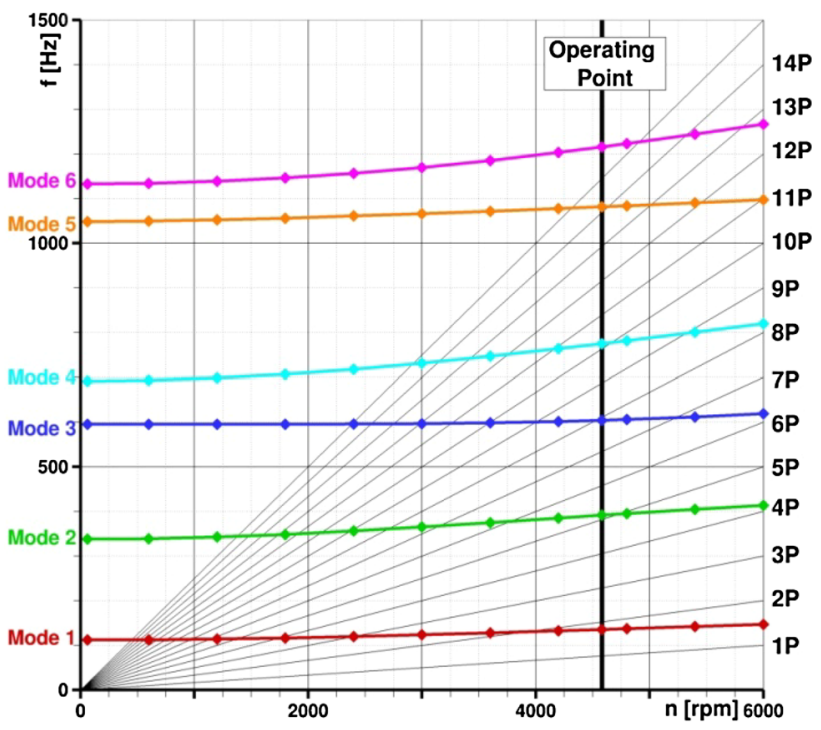

Fig. 9 1/5th scale front blade Campbell diagram

\section{Pre-test installation effects study}

In task 2.2.2.6 of the JTI SFWA project, which is led by Airbus, investigations are focused on the AI-PX7 CROR configuration at $1 / 5$ th scale. The associated wind tunnel model, termed Z49 by Airbus and ONERA, will be tested in isolated and semi-installed configurations at low-speed conditions in the DNW-LLF and as an isolated CROR at high-speed conditions in the ONERA S1 wind tunnel. Due to the relatively large scale, the models are heavily instrumented and will provide a broad range of steady and unsteady pressure data on the blades, the nacelle and pylon along with six-component rotating shaft balance data for each rotor. With the high-speed tests just recently performed in the summer of 2013, the project partners have been conducting pre-test, or "blind", CFD-CAA simulations with the aim of cross-plotting the results from the various methods and approaches used. For DLR-AS, another main focus was the study of the installation effect caused by the presence of the pylon. In general, despite some notable differences in the flow solvers as well as the methodology used by the various partners, the aerodynamic performance predictions so far fall within a scatter of around $3 \%$ in most cases. For the reference low-speed flight conditions at a speed of $M=0.23$, DLR-AS studies were focused on the installation effect due to an angle of attack as well as the interaction with the pylon. For the latter case, Fig. 10 shows a visualization of the vortical flow structures. In addition to the pronounced rotor-rotor interactions due to blade wake and tip vortices as well as blade potential flowfields, the pylon wake introduces an additional strong source of unsteady loading for the rotors during its passage behind the pylon. 


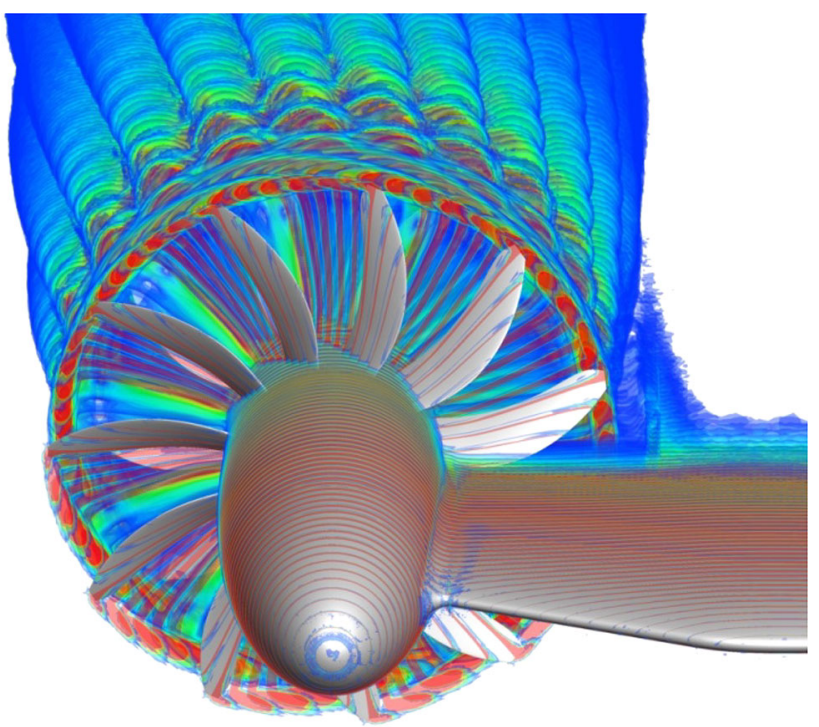

Fig. 10 Semi-installed Z49-CROR vortical flow structures

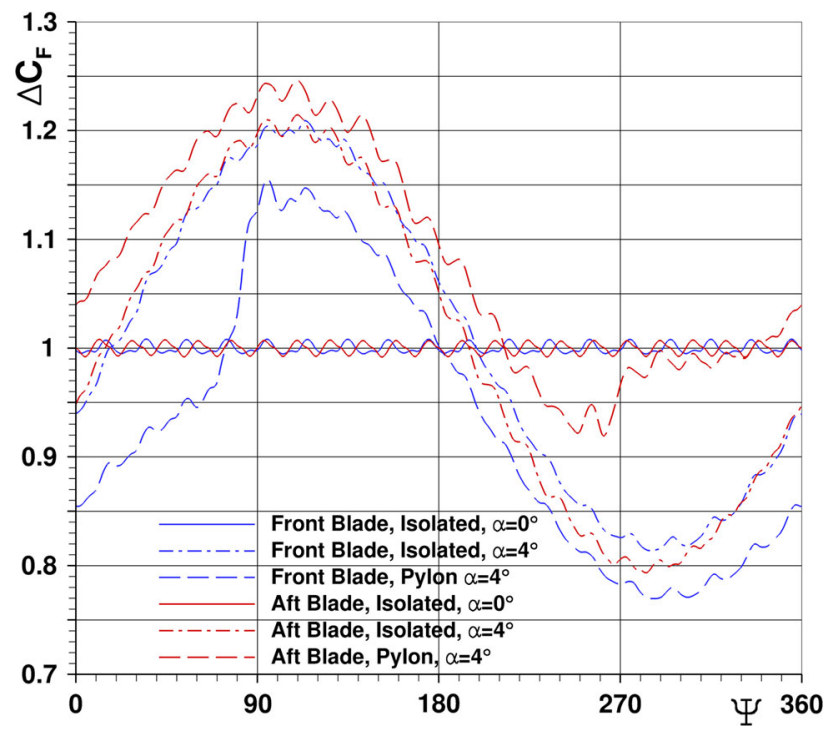

Fig. 11 Blade total force coefficient time history, normalized to mean values of isolated axial flow case

Figure 11 shows a comparison of the front and aft blade total force coefficient time history for the three low-speed cases studied so far. In the figure all front and aft blade values are normalized to the average value of the front and aft blade of the isolated CROR at axial flow conditions, respectively. For the isolated CROR at axial flow conditions the blade loadings show periodic oscillations around a constant mean value during one full rotor rotation. The unsteady loading is a result of the rotor-rotor interactions, with aft blades affected by front rotor blade wakes and tip vortices, while the front rotor is influenced by the aft blades potential flow.

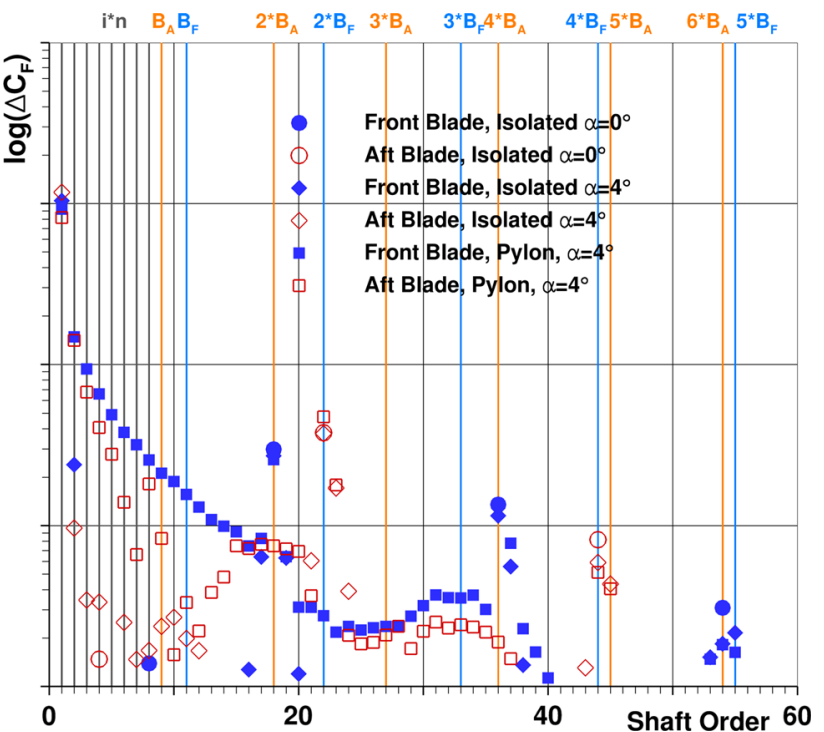

Fig. 12 Spectral analysis of unsteady blade total loading

This is evident in the spectral analysis of the unsteady loading, plotted in Fig. 12, where the dominant frequencies of a front blades periodic fluctuation are the even number higher harmonics of the aft blades blade passing frequencies. For an aft blade, the unsteady component of the loading occurs at the even number higher harmonics of the front blade passing frequency. For the fundamental frequency, the unsteady loading for an aft blade is larger than that of a front blade, indicating that blade wake and tip vortex impingement is the more substantial cause of rotorrotor interactions than is the potential flow effect.

When the isolated CROR is subject to an angle of attack of $\alpha=4^{\circ}$, the blades exhibit a sinusoidal loading cycle in addition to the rotor-rotor interaction fluctuations. For a front rotor's blade, the largest loading occurs on the downward sweep at an azimuthal position of around $\Psi=110^{\circ}$, while the magnitude drops below the values found for the isolated CROR at axial flow on the upward rotation, with a minimum at around $\Psi=290^{\circ}$. Obviously, the spectral analysis now shows the dominant unsteady loading at the rotor rotational speed, while only a marginal impact on the rotor-rotor interaction driven unsteady loading is seen.

The pylon wake impingement on the rotors leads to an abrupt increase in blade loadings, which occurs at an azimuthal angle of around $\Psi=90^{\circ}$ for a front and, to a lesser degree, at around $\Psi=270^{\circ}$ for an aft blade. In the Fourier analysis, the pylon effect is found to cause a richer frequency content of unsteady loading with only small changes in fluctuation amplitude versus the previous case at the dominant frequencies of $f=n, f=2 B_{\mathrm{A}}$ and $f=2 B_{\mathrm{F}}$. 


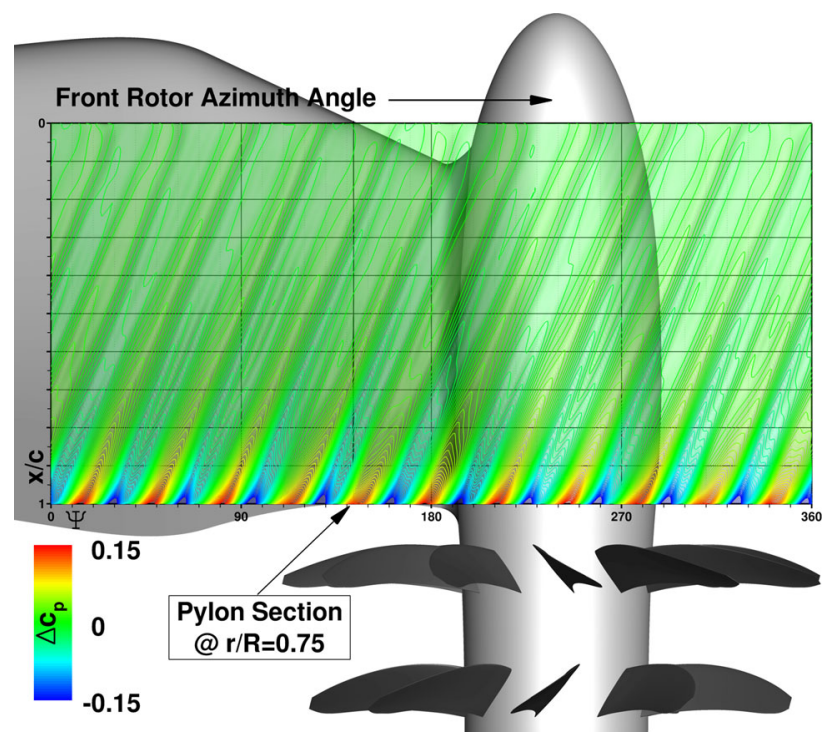

Fig. 13 Pylon pressure distribution time-history

Quite importantly, the rotor flowfield also has an upstream impact on the pylon. Figure 13 shows a contour plot of the time history of a pylon section pressure distribution at a spanwise position corresponding to a location at $r / R=0.75$ of the front rotor diameter. Dominant unsteady pressure fluctuations are evident at the trailing edge, which are seen to propagate all the way to the leading edge of the pylon. This strong unsteady component in the rotor-interaction driven pylon flow is evident in the periodic lift coefficient fluctuations during one full rotor rotation plotted in Fig. 14. The spectral analysis of this unsteady loading, shown in the figure inset, occurs primarily at a frequency associated with each of the front rotor blade's passage, i.e. the front rotor blade passing frequency. Only a very marginal direct interaction of the aft rotor on the pylon is detectable in the very small peak occurring at the aft rotors blade passing frequency. A small contribution to the unsteady loading is also seen at the first order interaction frequency as well as at a frequency corresponding to twice the shaft order. Since the latter corresponds exactly to the difference in the number of blades in the front and aft rotor, these two effects can be attributed to the impact of the rotor-rotor interactions. Since the individual blade loadings show a dependence on the interactions with the blades of the respective other rotor, as was discussed for Fig. 11, their upstream influence on the pylon reflect this through the unsteady pylon lift fluctuations at the two frequencies noted.

In addition to this unsteady effect of the rotors on the pylon, a comparison of the mean power-on lift coefficient with the pylon lift coefficient taken from a simulation omitting the rotors, shows, that due to the acceleration of the flow into the front rotor, the magnitude of the pylon lift

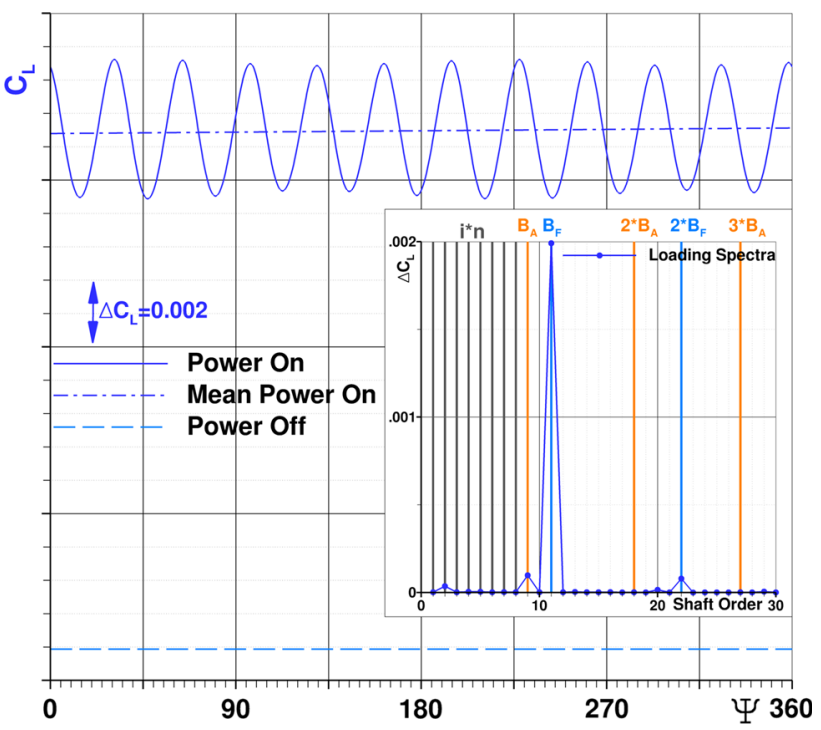

Fig. 14 Impact of the rotors on pylon lift development for the case at an angle of attack of $\alpha=4^{\circ}$

coefficient is notably increased. Therefore, the rotors influence on the pylon lead to important steady and unsteady installation effects.

Figure 15 plots a comparison of the ground noise directivities as computed with APSIM+ for a microphone array located at constant distance of around 11 rotor diameters from the engine axis. The directivities are split into tones associated to the front and aft rotors as well as those occurring at the interaction frequencies. The isolated CROR at axial flow conditions shows the focused directivity of the rotor tones, which radiate primarily in the direct vicinity of the plane of rotation of the rotors. In contrast, the interaction tones radiate strongly in the upand downstream directions, leading to the CROR-characteristic flat overall noise directivity in the farfield. For the isolated CROR at angle of attack, increases of around $2 \mathrm{~dB}$ in ground noise levels are found for both the front and aft rotor tones versus the axial flow case. This correlates with the higher blade loadings during the blades downward rotation, as was discussed in the analysis relating to Fig. 11. A smaller increase in the interaction tone levels is seen, which is in agreement with the relatively small impact on the magnitude of the unsteady rotor-rotor interaction found for the blade loadings in Figs. 11, 12 as the angle of attack is increased. The pylon has a more pronounced influence on the ground noise directivities, leading to increases in both front and aft rotor tones over and beyond what was seen for the angle of attack effect alone. Furthermore, the additional unsteady loading induced by the impingement of the pylon wake on the front blades leads to a large increase in the up- and downstream radiation of the front rotor associated tones. Since the 


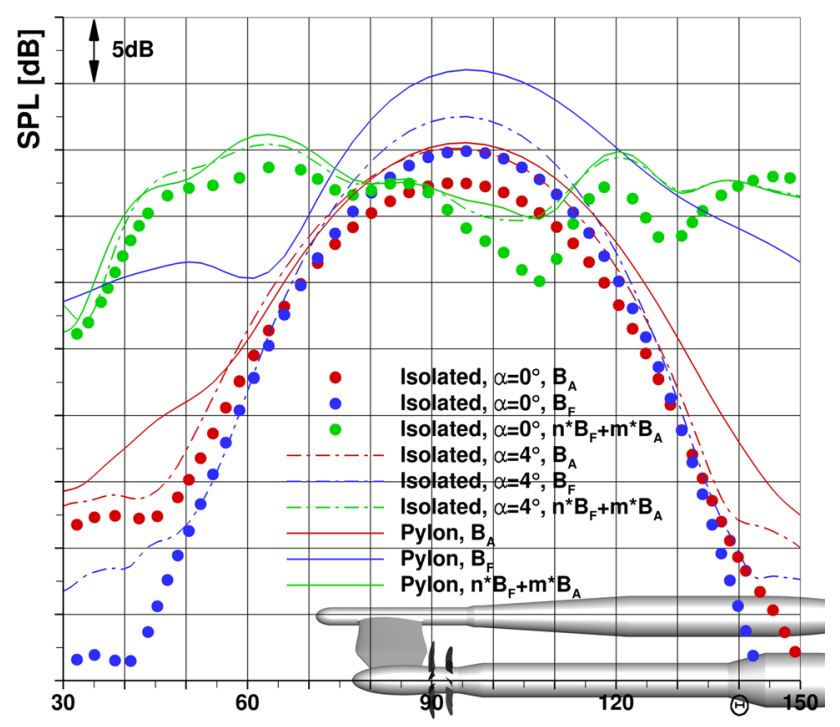

Fig. 15 Installation effect impact on tone ground directivity

pylon wake is already significantly dissipated in its interaction with the front rotor blades, its only minor effect on the aft rotor blades explains why aft rotor tone radiation in the up- and downstream direction are much less increased than the front rotor tones. Finally, the interaction tone ground noise directivity again shows only very small difference due to the installation effect of the pylon. This front rotor noise increase due to the pylon impact is potentially a big drawback for a pusher configuration CROR propulsion system. This is because it has a very negative impact in the fly-over noise certification scenario, where the prolonged exposure of a given observer on the ground to high levels of the noise is penalized in Effective Perceived Noise Level (EPNL) metric. Therefore some analysis of means to reduce the effect of the pylon wake impingement on the rotors have been undertaken in recent years, both inside the JTI SFWA project as well as independently [15].

In advance of the experimental results becoming available for the validation work, DLR has focused on some studies to further enhance the fidelity and accuracy of the numerical simulations. One possible shortcoming that has been identified relates to the process chain that draws on acoustically resolved CFD data only in the immediate nearfield of the rotors as input to the APSIM+ permeable surface CAA analysis. While this approach has many advantages and is generally found to be a preferred setup for a coupled CFD-CAA investigation, there are several reasons why a possible adaptation of this process chain might be necessary. Firstly, an analysis using the FW-H equation draws on the hypothesis that the propagation of the acoustic waves away from the permeable surface into the farfield occurs in a uniform flow. However, this is not strictly true even for an isolated CROR configuration, as there are clear flow non-uniformities in the up- and particularly in the downstream direction. These are expected to have some possibly important effects on the propagation of the sound waves away from the rotor in the nearfield. Another aspect is the limited extent of the Chimera surface used for the coupling between the TAU- and APSIM-codes. While it enclosed the rotors as the dominant noise sources and also inherently accounts for quadrupole contributions, it possibly neglects some relevant installation effects. These comprise aeroacoustic installation effects, such as reflections on the nacelle or pylon, as well as some additional potentially important noise sources. One such noise source could be the pylon itself, which, as shown in Fig. 13, clearly exhibits some strong unsteady pressure fluctuations. To study some of these aspects, a mesh refinement study was performed, which aimed to resolve acoustic wave propagation in the nearfield of the isolated CRORs nacelle in a region extending 1.5 rotor diameters in the up- and downstream as well as in the radial direction. This required a significant refinement of the nearfield nacelle mesh to be able to resolve acoustic pressures up to a frequency of $f=3 B_{\mathrm{F}}$ in the CFD simulation. A comparative uRANS simulation using two meshes was done for the isolated Z49 configuration at typical lowspeed take-of conditions at an angle of attack of $\alpha=4^{\circ}$, where a baseline mesh with $94 \mathrm{e} 6$ nodes was compared with the aeroacoustically adapted mesh with $150 \mathrm{e} 6$ nodes. Figure 16 plots the results of an evaluation of the noise emissions at a radial distance of $r / R=3$ from the engine axis below the CROR as extracted directly from the CFD simulation results. For comparison, results of an APSIM+evaluation based on the nacelle Chimera porous surface input data are included, as computed for the same virtual microphone positions. As the rotor meshes were identical for both the baseline and the refined mesh, only one FW-H result is shown. For all three cases, the figure shows directivities for the overall sound pressure level (OASPL) based on all tones up to and including the third harmonic of the front rotor blade passing frequency as well as the directivity of the first interaction tone.

The polar directivity shows the expected benefit of the refined mesh to capture higher frequency tones versus the baseline mesh in the upstream and radial directions in the direct evaluation of noise in the CFD results. This is manifested through higher overall sound pressure levels of around $1 \mathrm{~dB}$ in these regions when comparing the two CFD results and generally similar differences for the plotted interaction tone levels. The largest discrepancy between both the two CFD-based and the FW-H results is found in the downstream region. In comparison with the latter data, both CFD-based evaluations show significant differences in the directivity characteristics as well as localized increased noise emissions of around $4 \mathrm{~dB}$. The plotted interaction tone results indicate a more complex directivity pattern 


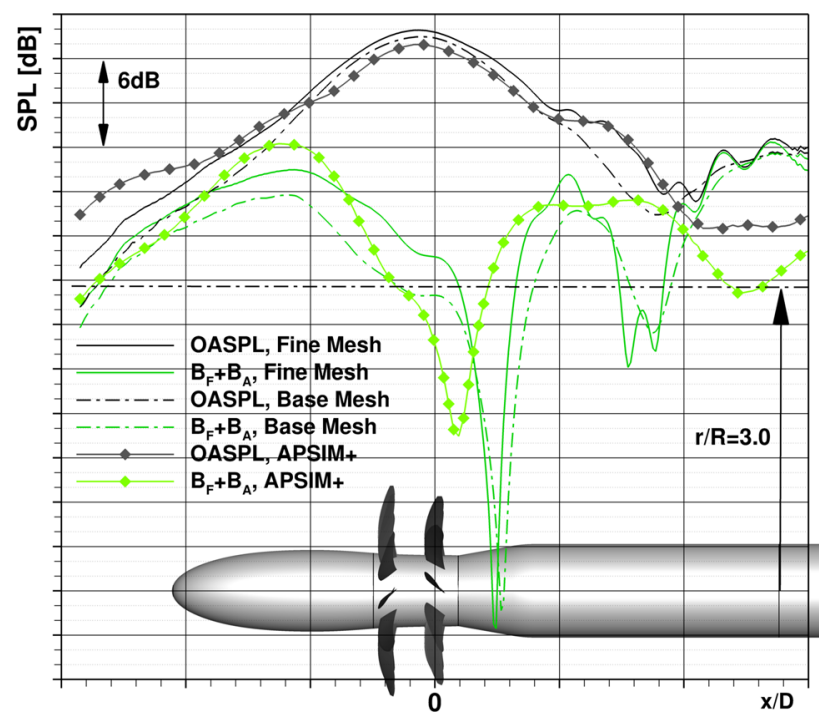

Fig. 16 Mesh refinement impact on uRANS-CFD resolved nearfield noise emission directivities for the isolated CROR at an angle of attack of $\alpha=4^{\circ}$

versus the porous surface results, which thus can be linked clearly with the impact of the strong non-uniform flow in the rotor wake on the noise propagation. Furthermore, comparing the two CFD-based evaluations shows that the better high-frequency resolution capability of the refined mesh as well as the better resolution of the complex aerodynamic flowfield results in additional small lobes in the most downstream portions of the directivities plotted in the figure [16]. The CFD simulations with such large meshes are naturally quite expensive, but the upcoming validation activities will be able to show if this approach is worth the extra computational cost to better match experimental data.

\section{Validation of CFD-CAA analysis}

The final major CROR-related work package in the JTI SFWA project, the DLR-led task 2.2.4.5 "Numerical Assessment of the Installed CROR Configuration", has the aim of furthering the understanding as well as the analysis capabilities of the aerodynamic and aeroacoustic installation effects at low-speed flight conditions. Aeroacoustics are the primary focus area, as noise emissions at take-off conditions are the dominant concern for the certification of a CROR-powered aircraft. The main input to this task is a series of wind-tunnel tests of the Z08 1/7th scale AI-PX7based pusher configuration CROR in the DNW-LLF facility. These experimental studies, initiated in 2012 and completed in the first half of 2013, encompassed performance and noise measurements of isolated, semi-installed as well as fully installed CROR configurations. While the reduced scale versus the Z49-model studied in task 2.2.2.6 constrained the instrumentation of the models slightly, the resulting database included results from a significant number of steady and unsteady pressure sensors on the blades, nacelle, pylon and aircraft, 6-component rotating shaft balance data for both rotors of the CROR as well as a wealth of microphone measurements.

The numerical analysis described here, which are focused directly on the validation of the CFD and CAA tools and approaches, are done for an initial test case of the isolated CROR configuration at axial flow conditions, matching exactly a test point in the wind tunnel tests.

In order to determine the best coupling strategy between the CFD and CAA simulations, the numerical approach described in Sect. 2 has been adapted slightly in order to test both the feasibility and the benefit of an extension of the resolution of acoustic waves in the CROR nearfield. While rotor meshes are generated in much the same manner as described previously, an additional Chimera block is used for the relevant CROR nearfield region, as shown in Fig. 17. For the nacelle, a block-structured mesh, adapted in its cell-sizes to resolve and propagate acoustic pressures corresponding to the 3rd front rotor blade passing frequency, are now used. A major focus of the mesh generation is a detailed study of the resolution requirements in the rotor-rotor interface region, as shown in Fig. 18. To ensure blade wakes from the front rotor are transferred with minimal losses across the Chimera boundary into the aft rotor block, the interface region ensures a 1:1 azimuthal matching of the cells on either side. For this particular case a total of 1,584 cells are used for the full analysis. In the simulations, a time-step study is performed, which successively reduces the size of the physical time step in the uRANS analysis up to a level that corresponds to a one-cell motion along the azimuth. Another important aspect of the present studies is a mesh refinement study for the isolated Z08-CROR configuration. While in most cases aeroacoustic requirements dictate the size of the mesh, for many purely aerodynamic-focused analyses a much less refined mesh is often sufficient.

Table 2 gives an overview of the mesh family that was created. The baseline mesh, sized for the requirements of the aeroacoustic analysis, is coarsened in all directions by a factor of 1.33 to obtain a medium-sized mesh and again to result in a coarse mesh. While the latter two no longer ensure an adequate resolution of acoustic waves in the desired high frequency range of interest in the CFD simulations, the expectation is that they will yield results in terms of CROR performance that are possibly fully sufficient for most aerodynamic aspects of interest and of course will also enable a robust mesh convergence study to be done. The CFD studies are done initially for the isolated 


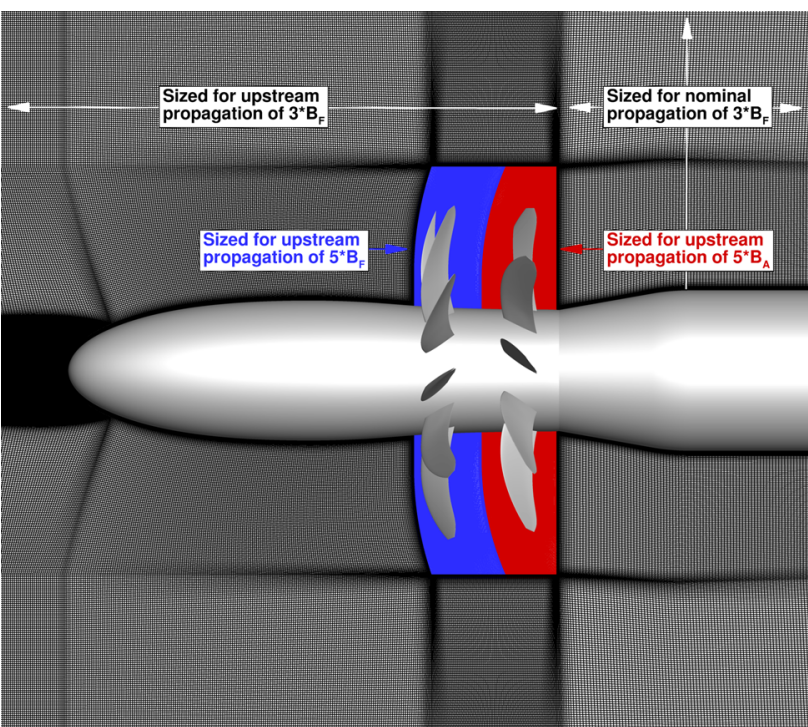

Fig. 17 Isolated CROR nearfield Chimera mesh setup

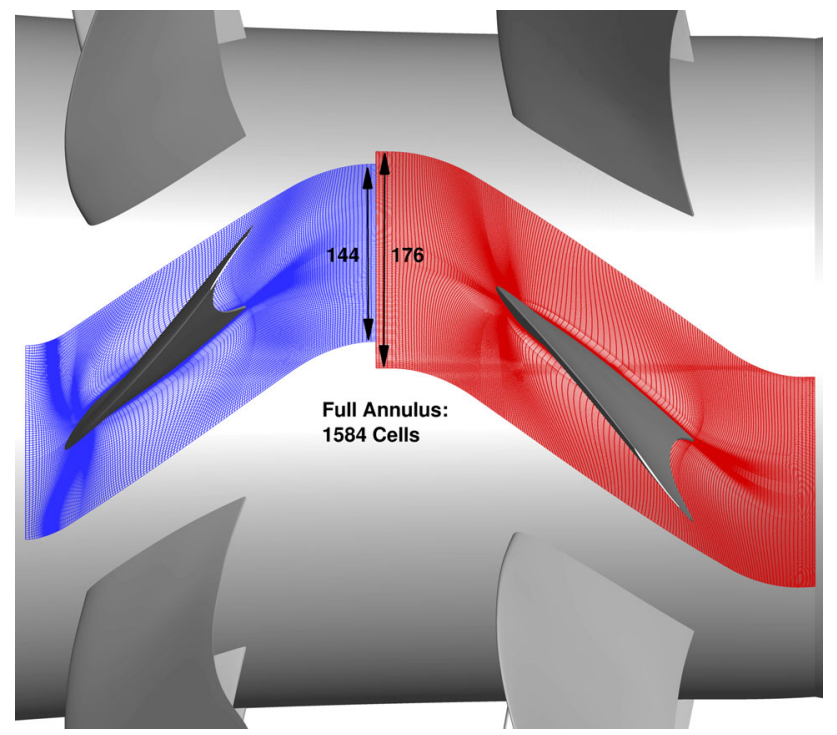

Fig. 18 Rotor-rotor interface meshing approach

CROR configuration, and replicate a wind-tunnel test point in terms of the take-off case flight conditions of $M=0.2$ and axial flow conditions as well as in the CROR operating point in terms of blade pitch and rotor rotational speed.

Figure 19 shows two instantaneous results of the medium mesh simulations, which show the impact of the time step size on the transfer of blade wakes through the Chimera interface on a circumferential surface at $50 \%$ of the front rotor radius. In the left half of the figure vorticity contours are shown for the simulation in which a time step size is used which results in a relative motion of two cells at the rotor-rotor Chimera interface. When compared with
Table 2 Isolated Z08-CROR mesh family overview

\begin{tabular}{llll}
\hline & Baseline & Medium & Coarse \\
\hline Farfield & $14.6 \mathrm{e}^{6}$ cells & $6.4 \mathrm{e}^{6}$ cells & $1.9 \mathrm{e}^{6}$ cells \\
Nacelle & $76.2 \mathrm{e}^{6}$ cells & $32.2 \mathrm{e}^{6}$ cells & $9.6 \mathrm{e}^{6}$ cells \\
Sting & $19.3 \mathrm{e}^{6}$ cells & $8.1 \mathrm{e}^{6}$ cells & $2.4 \mathrm{e}^{6}$ cells \\
Front Rotor & $42.9 \mathrm{e}^{6}$ cells & $18.5 \mathrm{e}^{6}$ cells & $5.4 \mathrm{e}^{6}$ cells \\
Aft Rotor & $53.9 \mathrm{e}^{6}$ cells & $22.8 \mathrm{e}^{6}$ cells & $6.8 \mathrm{e}^{6}$ cells \\
Total & $206.9 \mathrm{e}^{6}$ cells & $88.1 \mathrm{e}^{6}$ cells & $26.2 \mathrm{e}^{6}$ cells
\end{tabular}
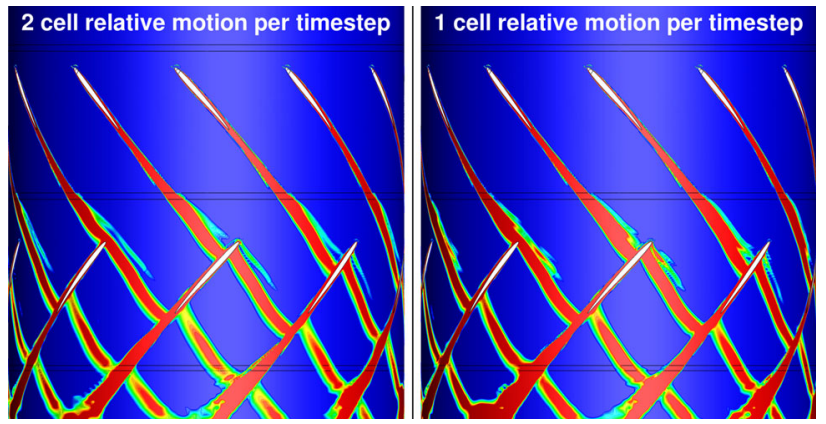

Fig. 19 Time step size influence on blade wake vorticity transfer through the Chimera interface for a circumferential slice at $50 \%$ blade radius in the medium mesh results

the result plotted in the right half of the figure, where the time step is reduced by half, resulting in a one cell relative motion a qualitative improvement in the wake transfer is evident. This is most noticeable in the more rapid decay of the front blade wakes as they interact with the aft blades for the case of the larger time step.

For all three meshes, Fig. 20 shows the performance metrics of the front and aft rotor normalized with the corresponding values in the experimental data. In each case the CFD results for the smallest time step employed are shown, as noted in the figure. For the individual rotor thrust all meshes show a very good agreement with the experimental data. The coarse mesh results give a nearly identical front rotor thrust as the experiments, while the aft rotor CFD data underpredicts thrust by $0.46 \%$. For the medium mesh, both front and aft rotor thrust prediction are marginally larger than the wind tunnel results by around $0.4 \%$, and the trend continues with the mesh refinement for the baseline mesh, where both thrust values are around $0.5 \%$ larger than the experimental values. A similarly degree of accuracy is achieved for the aft rotor power, with coarse, medium and baseline mesh results agreeing with the wind tunnel values with a marginal deviation of $-0.7,-0.2$ and $-0.09 \%$, respectively. Merely the front rotor power predictions show larger deviations, which range from $-4 \%$ for the coarse mesh to around $-3.8 \%$ for the medium and baseline mesh. 
Fig. 20 Front and aft rotor performance prediction deviations versus the experimental data
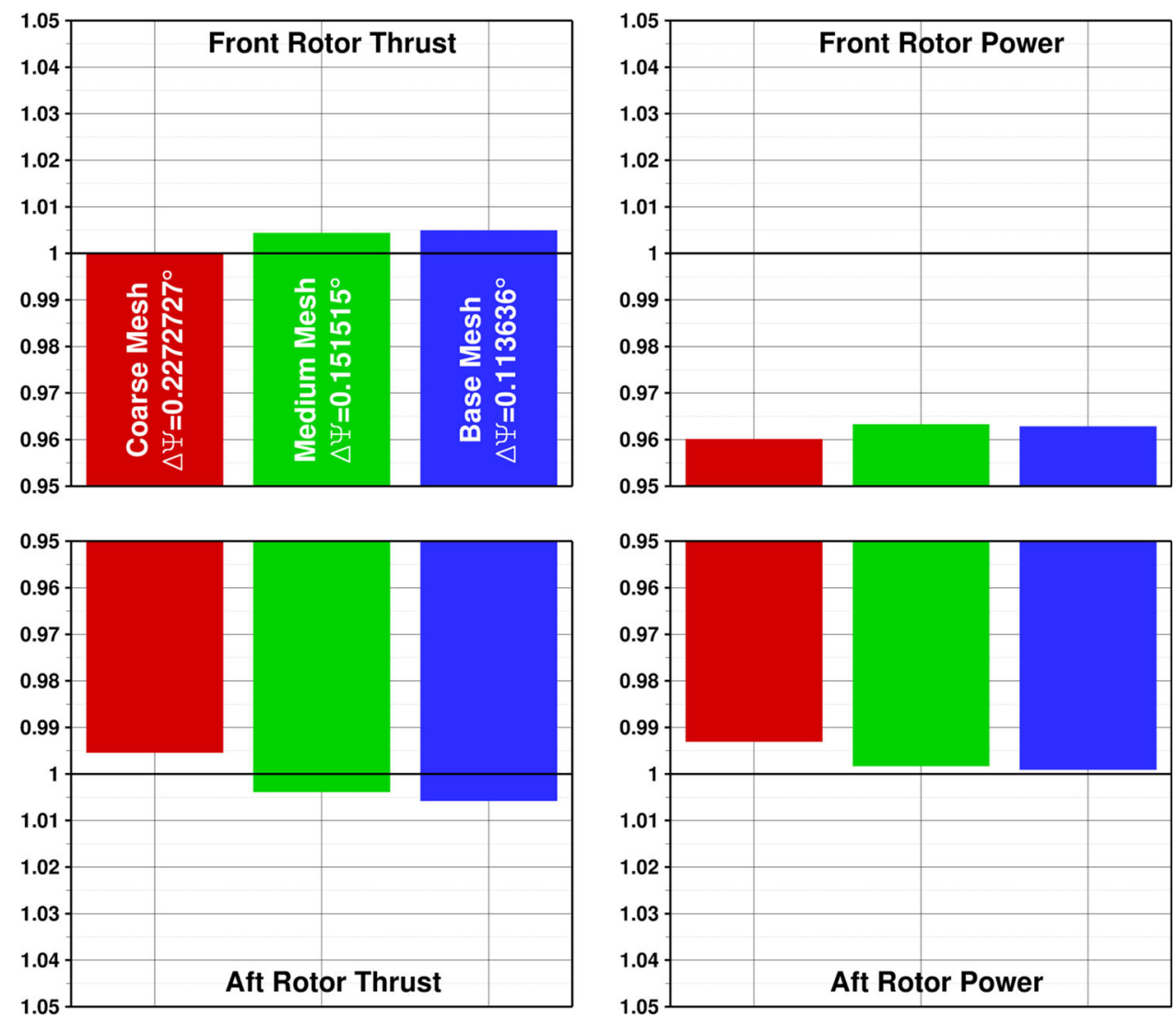

Table 3 CFD-predicted CROR performance metrics deviations from experimental data

\begin{tabular}{lllll}
\hline & $\begin{array}{l}\text { Thrust } \\
(\%)\end{array}$ & $\begin{array}{l}\text { Efficiency } \\
(\%)\end{array}$ & $\begin{array}{l}\text { Thrust split } \\
(\%)\end{array}$ & $\begin{array}{l}\text { Power split } \\
(\%)\end{array}$ \\
\hline Coarse & -0.2 & +2.9 & +0.4 & -3.3 \\
Medium & +0.4 & +3.0 & +0.1 & -3.6 \\
Base & +0.5 & +3.2 & -0.1 & -3.7 \\
\hline
\end{tabular}

For the CROR as whole, Table 3 lists the relative deviations of some relevant performance metrics for the two CFD results. Again, the agreement is very good, in particular in terms of the thrust values, while the slightly larger discrepancy seen in front rotor power predictions mentioned above also leads to slightly larger deviations in the CROR efficiency and power split values.

\section{Conclusion and outlook}

DLR-AS has contributed broadly to the Airbus-led effort in the frame of the 7th Framework EU JTI SFWA project aiming at an accurate and robust assessment of the potential of the CROR as a viable propulsion system for application on future short to medium range transport aircraft. Across a number of CROR-related work packages in the project multidisciplinary numerical tools, including the DLR-TAU CFD-Code and the DLR ASPIM+-FWH CAACode, have been applied and are in the process of being validated and important insight into the relevant flow physics for this novel powerplant have been gained.

Through two related studies based on a coupled CFDCAA analysis, the potential of applying front rotor trailing edge blowing for the reduction of interaction tone noise emissions has been demonstrated. When the CROR configuration ensures that front blade tip vortices do not impinge on the aft rotor, the reduction of the front rotor blade wakes through the use of trailing edge blowing enables peak noise reductions on the order of $2.5 \mathrm{dBA}$ and reductions in the up- and downstream interaction tone levels by up to $5 \mathrm{dBA}$. While the complexity and cost in terms of engine air offtake requirements clearly remain a challenge, at least in the latter case, possible optimization/ reduction of the spanwise extent of the blowing application could reduce air massflow requirements at little or no impact on the beneficial noise reduction results.

Ongoing work to account for blade flexibility in the multidisciplinary numerical analysis process chain at DLRAS has already been successfully employed to support wind tunnel model blade design. This has shown that aeroelasticity is surely an important consideration in the prediction of CROR performance and noise emissions, an 
aspect that is under further study in present work in the project. The next steps this effort are focused on improving the blade FE-models to account for the actually manufactured ply layup. With the cruise condition Z49 test in the ONERA S1 wind tunnel just recently completed, DLR-AS will draw on the experimental data to validate computations of both the static and dynamic aeroelastic deformations of the blades under test loading conditions and investigate the impact of blade aeroelasticity on performance and noise.

A large matrix of CROR simulations, including configurations that are aimed at improving the understanding of aerodynamic and aeroacoustic installation effects have been performed. These studies have yielded valuable insight into the complex flow physics of installed CROR propulsion systems, demonstrated the capabilities of the project partner's numerical analysis tools and given insight into areas of possible improvement in the CFD and CAA predictions.

Current and future activities will focus on the validation of all elements in the multidisciplinary numerical analysis process chain, drawing on the substantial amount of highvalue wind-tunnel data becoming available from the Airbus-led tests of the Z08- and Z49-CROR models at cruise and low-speed flight conditions. Current results for an isolated CROR configuration show that performance predictions utilizing the DLR TAU-Code are able to match the experimental test results with a high degree of accuracy on grids that range in size from quite representative for current industrial standards to highly refined. The validation activities will demonstrate if the latter's use results in markedly better predictions of the farfield noise emissions. Present pre-test results discussed in this paper indicate that non-linear propagation effects can have an important impact on the noise directivities. Thus, a study of the placement of the permeable input surface in the APSIM+analysis is planned to check if these non-linear propagation as well as aeroacoustic installation effects need to be accounted for in the coupled CFD-CAA analysis. Upcoming work will also focus on extending the validation activities to the semi-installed as well as the fully installed aircraft configurations.

Acknowledgments Airbus is greatly acknowledged for a fruitful collaboration in the JTI SFWA project and for permitting publication of this work.

Open Access This article is distributed under the terms of the Creative Commons Attribution License which permits any use, distribution, and reproduction in any medium, provided the original author(s) and the source are credited.

\section{References}

1. http://www.cleansky.eu/content/page/sfwa-0

2. Akkermans, R.A.D., et al.: "Handling of non-periodic contra rotating open rotor data"; AIAA 2012-2262. In: 18th AIAA Aeroacoustics Conference, Colorado Springs (2012)

3. Kroll, N., Fassbender, J.K.: "MEGAFLOW-numerical flow simulation for aircraft design". In: Notes on numerical fluid dynamics and multidisciplinary design, vol. 89, pp. 81-92. Springer, New York (2005)

4. Stuermer, A., Yin, J.: "The case for counter-rotation of installed contra-rotating open rotor propulsion systems". In: AIAA20122785, 30th AIAA Applied Aerodynamics Conference, New Orleans (2012)

5. Stuermer, A., Yin, J.: Installation impact on pusher CROR engine low speed performance and noise emission characteristics. Int $\mathrm{J}$ Eng Syst Modeling Simul 4(1-2), 59-68 (2012)

6. Negulescu, C.: Airbus AI-PX7 CROR design features and aerodynamics. SAE Int. J. Aerosp. 6(2), 626-642 (2013). doi:10. 4271/2013-01-2245

7. Spalart, P.R., Allmaras, S.R.: “A one-equation turbulence model for aerodynamic flows". In: AIAA1992-0439, (1992)

8. Jameson, A.: "Time dependent calculations using multigrid, with applications to unsteady flows past airfoils and wings". In: 10th AIAA Computational Fluid Dynamics Conference, Honolulu, (1991)

9. Madrane, A., Raichle, A., Stuermer, A.: "Parallel implementation of a dynamic unstructured chimera method in the DLR Finite Volume TAU-Code". In: 12th Annual Conference of the CFD Society of Canada, Ottawa, pp. 524-534, (2004)

10. Brentner, K., Farassat, F.: An analytical comparison of the acoustic analogy and Kirchhoff formulation for moving surfaces. AIAA J 36(8), 1379-1386 (1998)

11. Ffowcs Williams, J., Hawkings, D.: sound generation by turbulence and surfaces in arbitrary motion. Phil. Trans. R. Soc. Lond. 264(1151), 321-342 (1969)

12. Di Francescantonio, M., Giles, M.: A new boundary integral formulation for the prediction of sound radiation. J. Sound Vib. 202(4), 491-509 (1997)

13. Akkermans, R.A.D., Stuermer, A., Delfs, J.: "Assessment of front-rotor trailing-edge-blowing for the reduction of open rotor noise emissions". In: AIAA2013-2200; 19th AIAA/CEAS Aeroacoustics Conference, Berlin

14. Akkermans, R.A.D., Stuermer, A., Delfs, J.: “Active flow control for interaction noise reduction of contra-rotating open rotors". In: AIAA2013-3799; 49th AIAA/ASME/SAE/ASEE Joint Propulsion Conference and Exhibit (JPC), San Jose

15. Stuermer, A., Yin, J.: Pylon trailing edge blowing for the control of CROR unsteady blade loads. New Results Numer Exp Fluid Mech VIII 121, 715-722 (2013)

16. Colin, Y., Caruelle, B., Parry, A. B.: "Computational strategy for predicting CROR noise at low-speed Part III: investigation of noise radiation with the Ffowcs Williams-Hawkings analogy". In: 18th AIAA/CEAS Aeroacoustics Conference, Colorado Springs (2012) 